\title{
Some Notes on the Genus Cumanotus.
}

\author{
By \\ Nils Odhner. \\ Fil, Lic., Stockholm.
}

In 1908 Sir Charles Eliot published in the Journ. Mar. Biol. Assoc., Vol. VIII, No. 3, a paper "On the Genus Cumanotus"; in that paper he showed that Coryphella beaumonti, discovered and named by him in 1906,* was to be referred to the above genus, which had been first established by myself in 1907 from a study of the Norwegian C. laticeps, described at the same time as a new species. $\dagger$

Sir Charles Eliot also called attention to the striking resemblance of the two forms, and remarked that their identity was not improbable, though he assumed that there might be some differences in the denticulation of the jaws and the lateral teeth of the radula.

Through the kindness of Sir Charles Eliot and of Mr. De Morgan, Acting-Director of the Plymouth Laboratory, I have procured two specimens of $C$. beaumonti for comparison with the Norwegian C. laticeps, with a view to determine the distinguishing characters of the two forms.

In exterior appearance they are quite alike, and I have found no difference of a specific value in their habitus. The proportions of the body are nearly the same, as is evident from the following measurements (in $\mathrm{mm}$.) :-

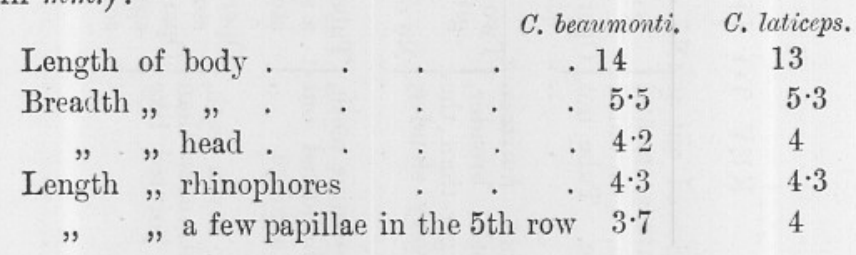

The height of the body was somewhat greater in $C$. becumonti than in $C$. laticeps, which probably depends on their varying states of preservation.

* "Notes on Some British Nudibranchs," l.c., Vol. VII, No. 3, 1906.

+ "Northern and Arctic Invertebrates, III, Opisthobranchia," K. Sv. Vet.-Akad. Handl., Bd, 41, No, 4, 1907. 
In both forms the soft parts fully agree in shape. On the head there are situated two small conical tentacles of the same size and position in both, connected by a low cutaneous fold. The rhinophores are close to each other, and are united at the base. The foot is extended, forming two pointed angles at the frontal sides, and is expanded laterally and posteriorly to a cutaneous border.

The arrangement of the dorsal papillae is also of the same character in both. They are set in about 12 transverse rows, the 3 foremost ones being placed in front of the rhinophores. The rows are in two groups, a pre-anal and a post-anal one, the first embracing 6 rows; the anus is situated dorso-laterally, immediately in front of the 7th row.

As to the number of papillae, this has been easy to determine in C. beaumonti, for all the papillae there were intact; in C. laticeps, on the other hand, they had fallen off to a great extent, and the statements here given are therefore deduced from the markings. One specimen of each form was examined.

The number of papillae was as follows :-

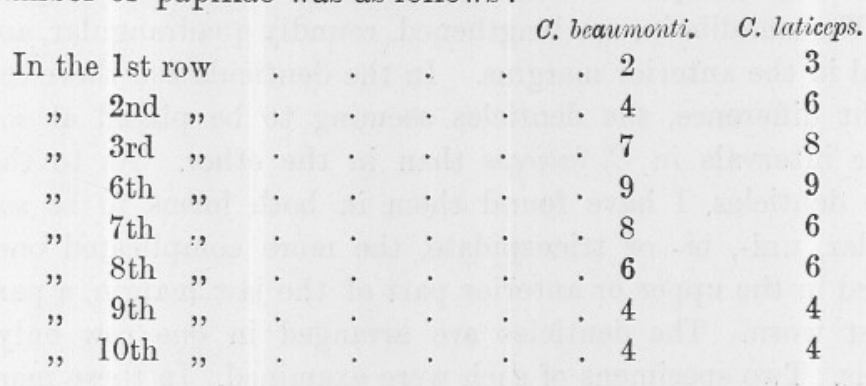

The unimportant difference which was present in the two specimens examined may be quite individual, and any attempt at deducing specific characters is therefore excluded.

Anatomically the papillae are of the same structure, for in both forms they are furnished, at the tips, with a saccus cnidophorus, which is connected with the liver process by means of a narrow, winding canal.

Of all the characters distinctive of the genus Cumanotus, the shape of the female copulatory organ is the most peculiar. To the sides of the bursa copulatrix there are attached two circular pads with a papillated margin, and these papillae are of the same number, 12 , in both forms. Such difference in dimensions as was observable in homologous parts is to be explained by their different stages of maturity.

Thus exteriorly the soft parts show an entire conformity, and from them consequently no specific characters are obtainable. There only 
remains the inner anatomy to be dealt with; but here I considered it unnecessary to compare the whole organization of the two forms in detail, and I have accordingly only examined the organs that are primarily of specific value, viz. the radula and the mandibulae.

The rows of the radula in $C$. beaumonti vary in number from 16 to 24 , according to Eliot; in $C$. laticeps I have found about 17 . The teeth are furnished in both forms with long, slightly curved cusps. The form and the denticulation of the median tooth do not present any differences. The lateral teeth are denticulated only on the inner sides. In the latest formed part of the radula, I have found the number of denticles of the laterals circa 25 in C. beaumonti and 18 in C. laticeps; in the older part above 25 and about 22 respectively. This slight difference is of no consequence, especially as the form and curvation of the lateral teeth are the same in the two specimens examined.

There remains only one more character to consider, the structure of the mandibulae, but here too I have found entire agreement. Their form and colour correspond, as do those of the whole bulbus pharyngeus too. The mandibulae are lengthened, roundly quadrangular, and denticulated in the anterior margins. In the denticulation there exists but a slight difference, the denticles seeming to be placed at somewhat greater intervals in C. laticeps than in the other. As to the shape of the denticles, I have found them in both forms to be somewhat irregular, uni-, bi- or tricuspidate, the more complicated ones being situated in the upper or anterior part of the jaw margin, a part which is most worn. The denticles are arranged in one row only at the margins. Two specimens of each were examined. In these mandibular characters also the forms agree wholly with one another.

It has consequently not been possible to find out any specific distinguishing points between the two forms; in all the characters they are alike. I therefore consider their identity to be proved. Nor are there any good reasons for their severance as varieties; it is hardly probable either that any would be obtainable from the characters of the living animal, though the colouring might doubtless be subject to some variation, as is usual with the Nudibranchs.

As a result of the above comparison, I consider the genus Cumanotus to consist of one species only, viz. C. beaumonti (Eliot, 1906), and regard my own species, C. laticeps, Odhner, 1907, as a synonym. $C$. beaumonti consequently has a wide distribution, being obtained in England as well as in Northern Norway. Further investigations will certainly show its occurrence also in the intermediate districts. 